\title{
Consumption Behaviours of Park Visitors and the Implications for Tourism Marketing: A Case in China
}

\author{
Zeng Benxiang \\ The Northern Institute, Charles Darwin University, Alice Springs, Australia \\ Email: benxiang.zeng@cdu.edu.au
}

Received November $9^{\text {th }}, 2012$; revised December $10^{\text {th }}, 2012$; accepted December $17^{\text {th }}, 2012$

\begin{abstract}
A survey of tourists to the protected areas in the Taibai Mountain (太白山) Region of China reveals a local domestic market, dominated by students and company employees. The market is attracted by the natural beauty of the Region, but not yet focused on nature based activities in the many protected areas. Given the Region's assured tourism future based on its natural and cultural characteristics, the survey data are used to discuss strategies for development. The fundamental issue is how to design tourism products targeting different tourist market segments which have different consumption preferences and behaviours and provide sustainable economic benefits to the local community while protecting the natural and cultural assets of this region.
\end{abstract}

Keywords: China; Local Poor; Market Segments; Tourism Development; Tourist Behaviours

\section{Introduction}

Tourists are the most important contributors to the world economy, as well as socio-cultural and eco-environmental systems. Tourist expenditure is the most important source of financial input to the tourism system. Tourist experiences within the tourism system are influenced by, and also potentially change, local social (including cultural) and ecological systems. Different tourists behave in very different ways and have different impacts including different expenditure, and bring different changes to local communities.

Tourist typologies are useful in tourism planning only to the extent that they realistically reflect tourist behaviour and the level of perturbation they bring to the receiving tourism system. That is, if different tourist types exert different levels of influence on the elements of the tourism experience and the change process, then manipulating tourist types is an available management strategy.

Mathieson and Wall (1982) propose nine types of criteria that could be used to identify tourist types and be useful in planning, consisting of 1) place of origin, 2) socio-economic demographic variables, 3) purpose for trip, 4) expenditure, 5) psychological characteristics, 6) length of stay, 7) accommodation preferences, 8) transportation style and 9) the level of use. However, a "natural taxonomy" of tourists and tourism types remains elusive. There appears little evidence to support universal application of many typologies in terms of tourist behaviour. They appear to be based more on characteristics of the tourist product presented (supply), than on demand aspects of tourists and their behaviour. Nevertheless, the influence of idiosyncratic typologies (Smith, 1978) and simple demographic segmentation of the tourist market has been profound (Pearce, 1982), although with some criticisms (such as Graf \& Ossig, 2002).

The use of psychographic segmentation has provided greater insight to tourist motivations, their underlying push-pull factors and behaviours (Bieger \& Laesser, 2000, 2002; Formica \& Uysal, 2002). This understanding has been applied to defining marketing strategies (Chen, 2003; Eftichiadou, 2001; Ekinci \& Chen, 2002; McCaskey, 2002), as well as strategic developments (Horneman, Carter, Wei, \& Ruys, 2002). While psychographic approaches appear to be the most useful way to segment tourist markets for strategic planning of tourism, it requires in-depth study of tourists and their motivations and perhaps becomes rapidly dated in a scenario of rapid change.

Tourist behaviour, like all human behaviour, is complex and ultimately unpredictable, but it is influenced by factors, normally considered under the banner of tourist psychology (Raj, 2004). Many ties between the psyche of tourists and their behaviour are held subconsciously; others are easily retrieved when thinking about a tourism-related activity. Commonly, these dimensions of tourist psychology have been discussed in terms of push-pull factors of tourist motivations (Uysal \& Jurowski, 1994; Yuan \& McDonald, 1990). Strong psychological factors that drive tourism behaviour include prior events and thoughts, thick descriptions of tourism consumption systems, and the consequences of tourists' visits (e.g. perceived quality of the visit experience, satisfaction with activities experienced; intentions to return, post-experiences, word-of-mouth communications). Weak psychological ties stimulate or inhibit tourism behaviour, although in most cases the presence of any one weak tie is necessary but not sufficient to result in specific tourism behaviours (Woodside, Caldwell, \& Albers-Miller, 2004). Travel activities and tourist demographics affect tourist consumption, including choice of products, product attributes, and store attributes. Swanson and Horridge (2004) found that the travel activities of tourists had positive correlations with souvenir consumption, while tourist demographics had no correlation. However, Suh and Gartner (2004) found that preference for a specific activity does not directly correlate with expenditure on the activity. This is typical of tourist psychology and behaviour studies that tend to be, at least, seemingly contradictory if gen- 
eralizations are sought.

Tourist profile affects tourism behaviour to some extent. Suh and Gartner (2004) suggested that, for both pleasure and business travellers, those from nearby homes tended to give most consideration to the "tangible" attributes (shopping), while the travellers from distant origins gave more consideration to "intangible" attributes (local culture). Regardless of origin, business travellers spent significantly more than pleasure travellers. In many cases, it is difficult to distinguish tourist behaviour by analysing market segments based on tourist profile (e.g. backpackers and holidaymakers), because the market is not solely comprised of "life change" or "rite of passage" holidaymakers, and differences are found between different groupings even in travellers with similar tourist profiles (Mohsin \& Ryan, 2003).

In protected areas in China, the numbers of tourists have been increasing rapidly in recent years. Developing suitable tourism products and targeting different tourism markets is important for sustainable tourism development. Understanding tourist behaviour and converting it into desired products is a crucial aspect of this endeavour. Of particular importance for China, is the development of products that are sustainable, that give tourism development a solid base for future growth and ultimately benefit local communities. This paper reports the results of a study that surveyed tourists from different origins and backgrounds to explore the effects of tourist behaviour on the local community. It identifies options for strategies of tourism development based on the findings.

\section{Case Study Area}

The study was conducted in a group of protected areas in the Taibai Mountain Region in Shaanxi, a western province of China. This is an area where tourism development has been increasing rapidly, and addressing widespread poverty is a major challenge.

Shaanxi is one of the less developed provinces in China. The annual net income per rural resident was a mere RMB 3438 (in 2009) (US $\$ 503.26$, i.e. US $\$ 1.38$ per day) (Bureau of Statistics of Shaanxi, 2010). This is much lower than the average national level of RMB5153 (US \$754.31, i.e. US \$2.07 per day) (National Bureau of Statistics of China, 2010). Local communities in the case study area had an even lower per capita annual net income for rural residents and per capita Gross Domestic Production (GDP) than the provincial average (Zeng 2008).

Being one of the most important habitats for Giant Panda, Gold Monkey and Golden Takin, three endangered species listed on the IUCN Red Book (IUCN, 2004), Taibai Mountain Region is presently undergoing rapid development to cater for the increasing number of tourists.

\section{Survey Methods}

A survey of tourists was conducted in July to August 2003 at tourist attraction entrances in the Taibai Mountain Region. A total of 500 tourists were surveyed with 271 used in the analysis. Demographic data were collected along with perspectives on tourism effects and tourism preferences, as well as spending details during the trip. The resultant combination of profile, expenditure data, preferences and perspectives permits triangulation of results by matching the contribution to the local economy and community (in quantitative terms) with perspectives (in qualitative terms). This permits derivation of recom- mendations for strategic action for developing tourism in the region.

\section{Results}

In this research, elements of the first five criteria types have been used. These were selected based on ease of collection through interview survey, knowledge of the existing market and the underlying basis of the study to track expenditure pattern and flow to, and through the community.

\section{Demographics}

\section{Tourist Origin}

Tourists were divided into those coming from: local counties, other counties of Shanxi Province, other provinces in China, and overseas. Most tourists visiting the Taibai Mountain Region are from the local (Shanxi) province, with 3.0\% from local counties and $49.8 \%$ from other parts (mainly Xi'An City, Baoji City (宝鸡市) and Xianyang City (咸阳市)). Other provinces (mainly the neighbouring provinces) contribute $46.1 \%$ of visitors, and only $1.1 \%$ comes from overseas. Thus, the current tourism market for Taibai Mountain Region is highly localised with considerable room for expansion, domestically and internationally, given appropriate marketing and an effective transportation system. For Taibai Mountain Nature Reserve (太白山 自然保护区), the percentage of external visitors, other than from Shanxi province, is much higher than that for Taibai Mountain Forest Park (太白山森林公园). Tourists visiting the Nature Reserve are typical "park" visitors seeking nature-based experiences rather than general holidays in a natural setting. This suggests, certainly supported by Taibai Mountain Nature Reserve's outstanding natural qualities, that the Reserve has the potentials to attract more external visitors interested in nature.

\section{Tourist Occupation}

Tourist occupation was divided into eight categories: student, business staff, factory worker, farmer, business person, public servant, retired senior and others. Students and company employees accounted for well over $50 \%$ of visitors to the Taibai Region (Figure 1). In contrast with developed nations (Horneman, Carter, Wei, \& Ruys, 2002), retired seniors accounted for

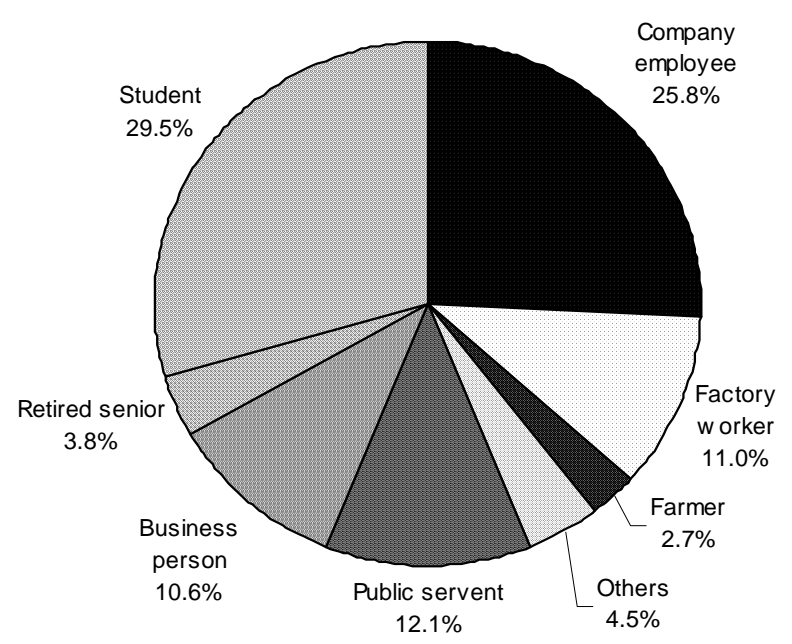

Figure 1.

Tourist occupation. 
only $3.8 \%$ of visitors. Farmers $(2.7 \%)$, the poorest demographic group, were the least represented. Therefore, the current market appears to be characterised by visitors with low levels of disposable income or minimal income.

\section{Destination Selection and Tourist Motivation}

\section{Nature as the Attraction}

Interviewees were asked to rank the reasons for visiting the Taibai Mountain Region from a given list. Nature was consistently ranked highest, followed by price, services and culture (Table 1). The importance of price reflects the employment status of the majority of visitors.

The importance of nature, especially the protected areas, was highlighted when interviewees were asked would they visit if the nature reserve/forest park did not exist. Most (55.0\%) answered "No", with 22.9\% answering "Yes" (22.1\% did not answer this question). These data suggest that, provided pricing levels can be maintained and services increased and improved, nature-based tourism will continue to be an important niche market for the Region, with considerable potential for expansion. While the tourism sector might be able to respond to growing tourist numbers, concern remains for the capacity of the Park management sector to respond to increased demand.

Given that the Taibai Mountain Region has a unique traditional country lifestyle and an amazing religious amalgamation of Taoism and Buddhism, it was expected that culture would be ranked higher as an attraction. The result probably reflects the interests of the localised market, but may be the result of the destination not marketing its cultural dimensions and the absence of culture-related tourism product. Certainly, culture based tourism is complementary to nature-based tourism, and strategic development of both would expand the market interested in visiting the Region, including international visitors. However, given the iconic status of the endangered and charismatic wildlife species, there is the danger that emphasis will be given to developing tourism product to exploit these attractions, without considering the inherent interest an external market would have for local culture. Any action to target a greater proportion of non-local visitors will need to consider the potential impact on local culture. This is particularly so given worldwide experience of the dangers of local cultures commodifying their way of living to enter the tourism system.

\section{Occupation and Destination Selection}

While all tourist occupation groups rank nature highly or the most important factor motivating a visit to the region, occupations have significant differences $(p<0.05)$ in how they ranked the provided list of pull factors (Table 2).

Public servants ranked nature the highest, followed by company employees, students, farmers and business people, while factory workers and retired seniors give nature the lowest average ranking. In contrast, they are most sensitive to price. It appears that with education and higher incomes comes a greater interest in nature. For low-income tourists, there is a need to balance attractions and costs. This is evident in the high ranking price is given by factory workers and retired seniors, but also by students.

Tourists from local counties rank nature the highest rank, followed by Shanxi tourists, China tourists and finally overseas tourists (Table 3). However, overseas tourists rank culture first in their priorities, while all domestic groups rank it lowest.
Similarly, the overseas tourists appear not to be price sensitive, ranking price lowest of the factors influencing destination choice. While domestic tourists tend to rank nature first and culture last, there is no statistical significance (significance $>$ 0.05 ) between groups' rank order. This is possibly a result of the variability given to ranking price and service.

While the number of overseas tourists interviewed was low, the relative importance given to culture and not to price is significant from a strategic planning perspective. It gives weight to the argument that developing cultural tourism products is crucial for the international market, and that, at least service and pricing may be almost incidental. Care must be taken with this interpretation of the results, because the sampled overseas tourists may be from one or more of Smith's (1978) "Explorer", "Elite", "Off-beat" or "Unusual" tourist types, which may not be service (and price) sensitive. If a tourism development strategy seeks to attract "Incipient mass", "Mass" or "Charter" types (see Smith 1978), then attention to service (and price) may be essential.

\section{Reason for Travelling and Satisfaction with the Taibai Experience}

Irrespective of place of origin and occupation, respondents indicated satisfaction with the tourism experience $(75.6 \%$ satisfied, $10.3 \%$ not satisfied and $14.0 \%$ did not answer). More than three-quarters of tourists interviewed were on holidays, although there were a relatively high number of tourists visiting to attend a convention (Figure 2). Convention attendees were public servants, company staff and professionals.

\section{Tourist Consumption Preferences}

\section{Tourists Prefer Comfortable Quality Hotels}

Different forms of accommodation can have different eco-

Table 1.

Factors affecting destination selection.

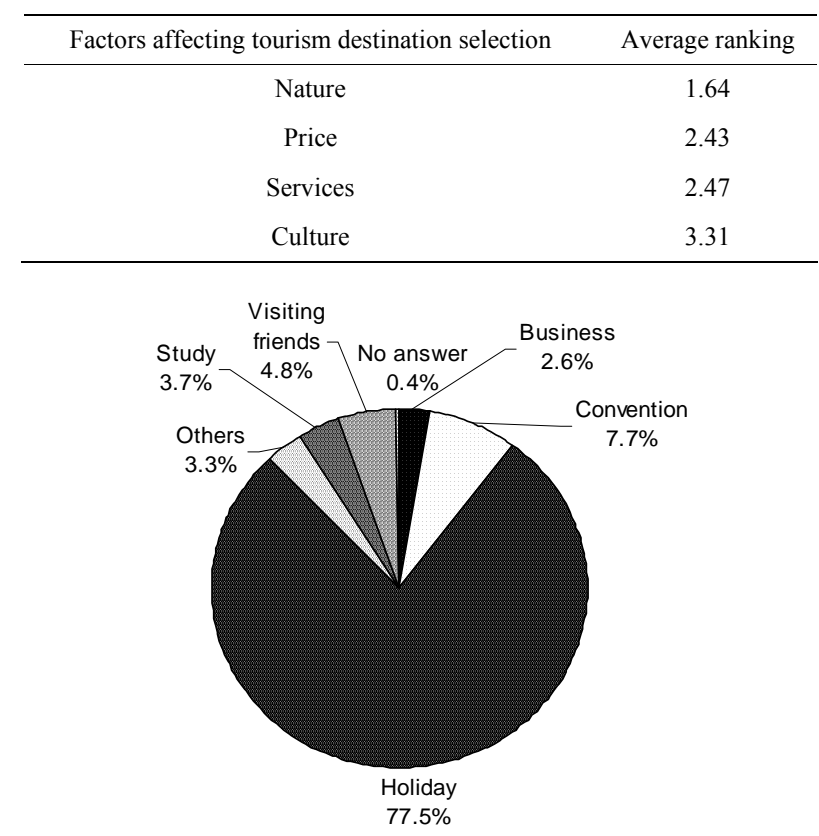

Figure 2.

Tourist visit motivation. 
Table 2.

Factors affecting tourism destination selection by tourist occupation.

\begin{tabular}{ccccc}
\hline Occupation category & $\begin{array}{c}\text { Nature ranking } \\
\text { (average rank order) }\end{array}$ & $\begin{array}{c}\text { Price ranking } \\
\text { (average rank order) }\end{array}$ & $\begin{array}{c}\text { Service ranking } \\
\text { (average rank order) }\end{array}$ & $\begin{array}{c}\text { Culture ranking } \\
\text { (average rank order) }\end{array}$ \\
\hline Others & $1.09(1)$ & $3.25(4)$ & $2.36(2)$ & $3.09(3)$ \\
Public servant & $1.23(1)$ & $2.86(2)$ & $2.43(3)$ & $3.41(4)$ \\
Company employee & $1.62(1)$ & $2.37(3)$ & $2.27(2)$ & $3.49(4)$ \\
Student & $1.67(1)$ & $2.18(2)$ & $2.84(3)$ & $3.17(4)$ \\
Farmer & $1.70(1)$ & $2.76(3)$ & $2.08(2)$ & $3.22(4)$ \\
Business person & $1.75(1)$ & $2.29(2)$ & $2.46(3)$ & $3.50(4)$ \\
Factory worker & $2.20(2)$ & $2.00(1)$ & $3.00(4)$ & $2.80(3)$ \\
Retired senior & $2.22(1)$ & $2.22(1)$ & $2.22(1)$ & $3.00(4)$ \\
Not indicated & $2.33(2)$ & $2.33(2)$ & $1.83(1)$ & $3.50(4)$ \\
Total & $1.64(1)$ & $2.43(2)$ & $2.47(3)$ & $3.31(4)$ \\
\hline
\end{tabular}

Table 3.

Ranking factors affecting tourism destination selection by different tourist origin.

\begin{tabular}{ccccc}
\hline Origin category & $\begin{array}{c}\text { Nature ranking } \\
\text { (average rank order) }\end{array}$ & $\begin{array}{c}\text { Price ranking } \\
\text { (average rank order) }\end{array}$ & $\begin{array}{c}\text { Service ranking } \\
\text { (average rank order) }\end{array}$ & $\begin{array}{c}\text { Culture ranking } \\
\text { (average rank order) }\end{array}$ \\
\hline Local & $1.37(1)$ & $2.67(3)$ & $2.43(2)$ & $2.83(4)$ \\
Shanxi & $1.57(1)$ & $2.41(2)$ & $2.58(3)$ & $3.31(4)$ \\
China & $1.72(1)$ & $2.42(3)$ & $2.35(2)$ & $3.34(4)$ \\
Overseas & $2.00(2)$ & $4.00(4)$ & $2.00(2)$ & $1.00(1)$ \\
Total & $1.64(1)$ & $2.43(2)$ & $2.47(3)$ & $3.31(4)$ \\
\hline
\end{tabular}

nomic effects on the local economy. Vaughan, Farr and Slee (2000) considered agro-tourism (farm-based) and non-agrotourism (hotels) forms of accommodation in Exmoor National Park, UK. They found that both forms of accommodation created similar levels of employment and income per unit of visitor spending; although non-agro tourism generally created higher levels of income per unit of visitor spending, while agro tourism created more employment per unit of visitor spending.

This study found that tourists generally prefer comfortable, quality (government rated) accommodations irrespective of their occupation and hence income level (Figure 3).

While the number of hotels in the Taibai Region appears to match demand, only $55.3 \%$ of respondents reported being accommodated at the standard of hotel desired. Thus, in the Taibai Mountain Region, given the low importance given to service standard in tourist destination choice, there appears to be some misalignment of hotel diversity and tourist expectations; or there are tourist density and facility level problems. While data were not collected to clarify the issue here, the impression gained from undertaking the work was that tourists would appreciate delivery of a higher service and quality standard for all accommodation forms. Clearly, this is a matter to be address at an early time if tourism is to grow and be sustainable in the Region.

\section{Tourist Preference for Restaurants}

Nearly $70 \%$ of tourists indicated they preferred to dine in formal restaurants (hotel and quality (government regulated)

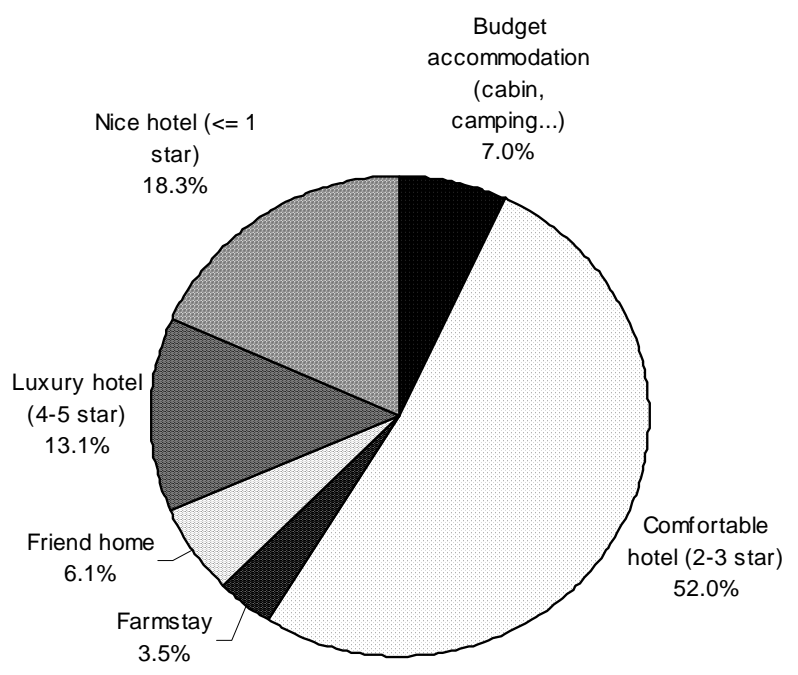

Figure 3.

Tourist preference in accommodation selection.

restaurants), rather than in informal restaurants, including roadside food services run by local people (Figure 4).

However, many tourists indicated a desire to experience the local cuisine but were reticent because of concern for hygiene. If local cuisine is to be developed as a tourism product then input is needed to assure visitors that hygiene and sanitation meet minimum standards. This will probably require govern- 
ZENG B. X.

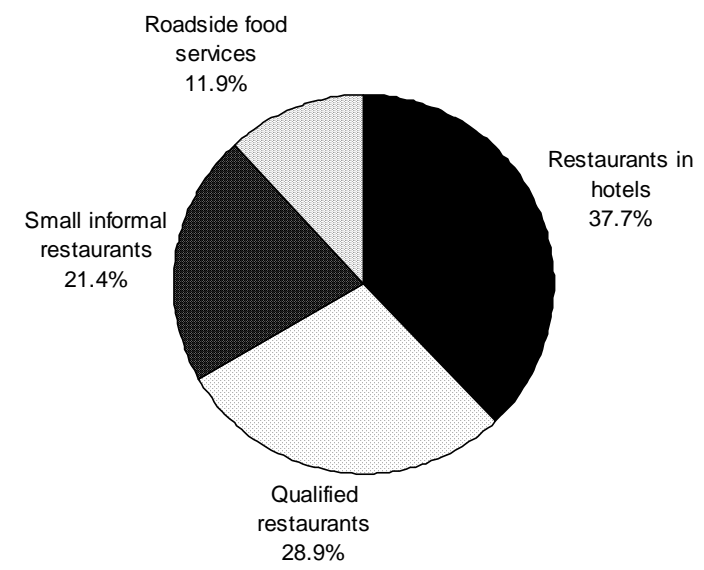

Figure 4.

Tourist preference in restaurant selection.

ment investment in the training of local residents, especially roadside food outlets. The benefits of such investments lie in the fact that purchases from informal food outlets means income goes directly to the local community and may be a major factor in poverty alleviation. For quality and hotel restaurants, this result suggests that it would be good business practice to serve tourists with local special traditional food.

\section{Tourist Spending Behaviours}

The structure of tourist spending affects the degree to which economic benefit of tourism flows to a community. Equally, different tourist types have different spending behaviours, leading to different effects on the local economy and households. In a study in the North West Province of South Africa, Saayman, Saayman and Rhodes (2001) found that most tourist expenditure is on accommodation (33\%), followed by shopping and souvenirs $(21 \%)$ and entertainment $(18 \%)$. They concluded that tourism has a positive impact on a country's balance of payments, foreign exchange earnings, gross domestic product and employment. The magnitude of this favourable impact depends, however, on the multiplier effect, which in turn depends on the extent of leakages from the economy.

\section{Structure of Tourist Spending}

Tourists to the Taibai Mountain Region spend an average of US $\$ 49.12$ during a visit. The structure of tourist expenditure shows that travel, food, accommodation and entry fees are the major items and account for nearly $65 \%$ of total expenditure (Figure 5). In contrast, local products and souvenir consumption is small, $5.9 \%$ and $4.6 \%$ respectively. Expenditure on entertainment $(2.9 \%)$, carriers and guides $(2.0 \%)$ are even lower (Figure 5). These latter items are often suggested as areas where local communities can gain financially from increased tourist activity. While this result might reflect the purchasing preferences of the largely local Chinese visitor, it might also suggest a shortage of local tourist product, including local produce, distinctive souvenirs and entertainment events that display local traditional culture, guided tours and destination interpretation services. It suggests that the development of such products probably lags behind tourism development, yet these are areas where local unskilled people might gain from tourism activity.

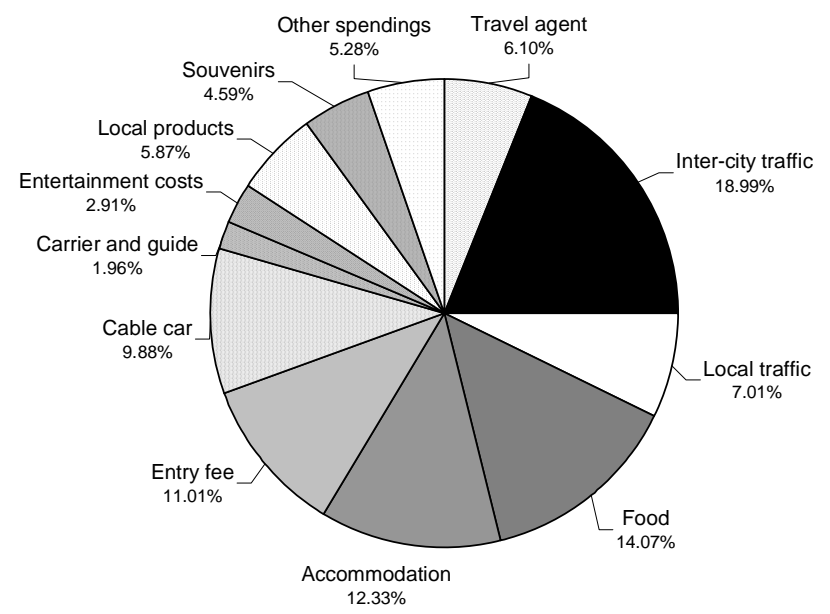

Figure 5.

Tourist spending structure in the Taibai Mountain Region, China.

\section{Tourist Origin and Occupation and Spending Patterns}

The differences in expenditure for various tourist profiles are significant. This was found to be the case in the Taibai Mountain Region where tourist expenditure varied considerably, depending on the origin of the tourist. Total spending by Chinese tourists from outside Shanxi is US \$62.21, significantly higher than the US $\$ 38.35$ spent by tourists from Shanxi Province and the US $\$ 14.78$ spent by tourists originating locally (Table 4). In addition, expenditure on local products follows a similar trend. A Pearson Correlation statistic between spending on local products and total tourist expenditure reveals a highly significant correlation $\left(\mathrm{n}=173, \chi^{2}=0.745, p=0.000(<0.01)\right)$. That is, the further a tourist has to travel to reach the Region, the greater will be their total expenditure as well as their expenditure on local products. Thus, developing external markets (other provinces in China and from overseas) is likely to provide higher tourist receipts than attracting the local market and will probably result in financial benefits flowing further down the household income brackets.

Occupation also affects spending pattern. Farmers spend an average of US $\$ 94.73(n=18)$ on a visit to the Taibai Mountain Region, followed by public servants (US $\$ 56.08, \mathrm{n}=19$ ) and business employees (US $\$ 54.28, \mathrm{n}=41$ ). Those that spend the least are retired seniors (US $\$ 36.09, \mathrm{n}=8$ ), students (US $\$ 34.50$, $\mathrm{n}=51$ ) and factory workers (US $\$ 27.59, \mathrm{n}=4$ ) (Table 5). Expenditure on local products follows a similar trend.

It is not surprising that low-income groups spend less during their trip and less on local products than higher income visitors. However, it is really surprising that farmer tourists spend the most money both in total and on local products. This can be explained by only farmers who are wealthy can travel. This is supported by considering the origin of this group. Most come from relative developed areas $(27.8 \%$ are from Baoji and $\mathrm{Xi}$ 'an which are the two largest cities in Shanxi, and $66.7 \%$ are from the developed provinces of Beijing, Shanghai and Guangdong).

\section{Conclusions and Discussion}

Strategically and from an economic benefit to the region perspective, the target tourist groups for tourism development in the Taibai Mountain Region need to be selected based on both per capita expenditure and tourist number. Based on the 
Table 4.

Tourist origin and tourist spending.

\begin{tabular}{cccc}
\hline Tourist origin & $\begin{array}{c}\text { Total spending } \\
\text { (A) (US \$) }\end{array}$ & $\begin{array}{c}\text { Spending on local } \\
\text { products (B) (US \$) }\end{array}$ & B/A (\%) \\
\hline Local & 14.78 & 0.35 & 2.4 \\
Shanxi & 38.35 & 1.72 & 4.5 \\
China & 62.21 & 4.20 & 6.8 \\
\hline
\end{tabular}

Table 5.

Tourist occupation and tourist spending.

\begin{tabular}{cccc}
\hline Tourist occupation & $\begin{array}{c}\text { Total spending } \\
\text { (A) (US \$) }\end{array}$ & $\begin{array}{c}\text { Spending on local } \\
\text { products (B) (US \$) }\end{array}$ & B/A (\%) \\
\hline Factory worker & 27.58 & 0.30 & 1.1 \\
Student & 34.50 & 1.20 & 3.5 \\
Retired senior & 36.09 & 1.48 & 4.1 \\
Merchant & 38.50 & 2.93 & 6.0 \\
Others & 49.25 & 1.61 & 3.3 \\
Not indicated & 53.94 & 2.42 & 4.5 \\
Company employee & 54.28 & 3.77 & 6.9 \\
Public servant & 56.08 & 3.68 & 6.6 \\
Farmer & 94.73 & 6.43 & 6.8 \\
\hline
\end{tabular}

existing market, farmers, public servants and business employees outside of the region are the most important target groups, because they have the highest expenditure patterns and moderate tourist numbers. Of the groups with the lowest per capita spending, students must be considered as an important economic contributor to local economy and local households because of their large number. Greater attention to this group is also warranted given their relatively low demand for infrastructure and services and hence, represent a "soft option" for manageable tourism development where the local community can gain experience with tourism, but working with a market that is less demanding than others. However, if rapid economic growth is the sole rationale for tourism development then the travel agency business perception that "both the current perceived significance of student markets and the potential significance of this market in the future is very low" (Shanka \& Taylor, 2002) may well be true. However, there has been little research undertaken to understand the motivations and needs of this group (Dosen \& Prebezac, 2003), and, for example, student study tours may be a form of sustainable tourism that can make a substantial economic impact on host countries (Fleenor, Toh, \& Arnesen, 2003).

The Taibai Mountain Region is currently a nature-based tourism attraction; however, its future may lie in developing both nature and culture based products and related marketing images, especially if the international market is a target. Domestic tourists from other provinces and international tourists spend more money both in total and on local products. Given that these markets are currently largely untapped, they are important targets for marketing and product development to suit their expectations and holiday behaviours. Given suitable education of local entrepreneurs then the benefit to the local economy and local community development is likely to be significant if even a modest penetration into these markets is possible.

Existing tourists prefer quality hotels and restaurants and the current level and range of facilities appears not to match demand. Therefore, irrespective of the potential to attract overseas and the distant domestic market, it appears necessary to develop a greater diversity of quality hotels and food services, and upgrade quality generally. At the same time, if increasing tourism benefits to the poorer members of the local community is an objective, then the informal accommodation and food \& beverage sectors must be strengthened and improved to be quality and at a reliable standard of quality.

Holiday makers are the main component of tourists in the Taibai Mountain Region. However, to attend a convention is becoming more and more important motivation for visitors to the region. Convention attendees have relatively high expenditure patterns both in total and on local products during their trip. Considering their relatively higher consumption ability, targeting and expanding this market seems to be another soft option for increasing tourism revenues, although economic benefits to local poor people is likely to be less than strategies that focus on alternative markets. However, to grow the share of this market will require investment in quality convention products such centres, accommodation and ancillary products such as special study day tours, convention souvenirs and local cultural performances.

The Taibai Mountain Region faces an assured tourism future based on its natural and cultural qualities. The issue for tourism development planning is how fast should tourism grow, what should be the marketing image, who should be the target markets and what level of impact is acceptable if a sustainable future is the ultimate tourism goal. The study of tourist behaviours and their effect on the local community reported here provides insight to the implications of various strategies. A rapid growth, economic maximisation approach requires responding to the existing markets and expanding into the international and distant domestic markets. The danger is that the local community will be left behind and economic benefits will not filter down. The alternative of slower growth and maximisation of benefits to the local community does not exclude the former. The region is fortunate in not being tourism resource poor, rather it is tourism product poor, with a deficit of both economic and social capital to ensure benefits truly accrue to the local community. It seems that strategic (government) interventions are needed realise both tourism futures.

\section{REFERENCES}

Bieger, T., \& Laesser, C. (2000). Segmenting travel situation on the basis of motivation and information collection by the traveller. Tourism Review, 55, 54-64. doi:10.1108/eb058334

Bieger, T., \& Laesser, C. (2002). Market segmentation by motivation: The case of Switzerland. Journal of Travel Research, 41, 68-76.

Bureau of Statistics of Shanxi (2010). Statistical communiqué of Shanxi Province on the 2009 national economic and social development. URL (last checked 20 July 2011).

http://knews.shaanxi.gov.cn/0/1/65/365/369/79324.htm

Chen, J. S. (2003). Market segmentation by tourist's sentiments. Annals of Tourism Research, 30, 178-193. doi:10.1016/S0160-7383(02)00046-4

Dosen, O., \& Prebezac, D. (2003). Consumer behavior in tourismAttitudes and motivators as criteria for segmentation of tourism market. Acta-Turistica, 15, 118-143. 
Eftichiadou, V. (2001). A multi-motive segmentation of urban visitors: The case of Liverpool. The Journal of Tourism Studies, 12, 2-10.

Ekinci, Y., \& Chen, J. (2002). Segmenting overseas British holidaymakers by personal values. Journal of Hospitality and Leisure Marketing, 9, 5-15.

Fleenor, C. P., Toh, R. S., \& Arnesen, D. W. (2003). Student study tours: Impact on tourism. Tourism Analysis, 7, 277-281. doi: $10.3727 / 108354203108750030$

Formica, S., \& Uysal, M. (2002). Segmentation of travelers based on environmental attitudes. Journal of Hospitality and Leisure Marketing, 9, 35-49.

Graf, L., \& Ossig, C. (2002). Review of the concept of travel typologies: The case of Switzerland. Tourism Review, 57, 28-32. doi:10.1108/eb058392

Horneman, L., Carter, R. W., Wei, S., \& Ruys, H. (2002). Profiling the senior traveller: An Australian perspective. Journal of Travel Research, 41, 23-37.

IUCN (2004). 2004 IUCN red list of threatened species. URL (last checked 30 July 2010). www.redlist.org

Mathieson, A., \& Wall, G. (1982). Tourism: Economic, physical, and social impacts. London, New York: Longman.

McCaskey, D. (2002). If you're not talking segmentation, you're not talking marketing. Hospitality Review, 4, 9-16.

Mohsin, A., \& Ryan, C. (2003). Backpackers in the northern territory of Australia-Motives, behaviours and satisfactions. International Journal of Tourism Research, 5, 113-131. doi:10.1002/jtr.421

National Bureau of Statistics of China (2010). Statistical communiqué of the People's Republic of China on the 2009 national economic and social development. URL (last checked 20 July 2011).

http://www.stats.gov.cn/tjgb/ndtjgb/qgndtjgb/t20100225_402622945. htm

Pearce, P. L. (1982). The social psychology of tourist behaviour. Oxford: Pergamon Press

Raj, A. (2004). The tourist-A psychological perspective. New Delhi:
Kanishka Publishers \& Distributors

Saayman, M., Saayman, A., \& Rhodes, J. A. (2001). Domestic tourist spending and economic development: The case of the north west province. Development Southern Africa, 18, 443-455. doi: $10.1080 / 03768350120083888$

Shanka, T., \& Taylor, R. (2002). Travel agencies' perception of higher education students as a viable market. Anatolia, 13, 33-47. doi:10.1080/13032917.2002.9687013

Smith, V. L. (1978). Tourism and behaviour. Williamsburg: Department of Anthropology.

Suh, Y., \& Gartner, W. C. (2004). Preferences and trip expendituresA conjoint analysis of visitors to Seoul, Korea. Tourism Management, 25, 127-137. doi:10.1016/S0261-5177(03)00056-6

Swanson, K. K., \& Horridge, P. E. (2004). A structural model for souvenir consumption, travel activities, and tourist demographics. Journal of Travel Research, 42, 372-380. doi:10.1177/0047287504263031

Uysal, M., \& Jurowski, C. (1994). Testing the push and pull factors. Annals of Tourism Research, 21, 844-846.

doi:10.1016/0160-7383(94)90091-4

Vaughan, D. R., Farr, H., \& Slee, R. W. (2000). Estimating and interpreting the local economic benefits of visitor spending: an explanation. Leisure Studies, 19, 95-118. doi:10.1080/026143600374789

Woodside, A. G., Caldwell, M., \& Albers-Miller, N. D. (2004). Broadening the study of tourism: introduction to the special issue on the consumer psychology of travel/tourism behaviour. Journal of Travel and Tourism Marketing, 17, 1-6. doi:10.1300/J073v17n01 01

Yuan, S., \& McDonald, C. (1990). Motivational determinants of international pleasure time. Journal of Travel Research, 29, 42-44. doi: $10.1177 / 004728759002900109$

Zeng, B. (2008). Tourism development and local poverty: A case study of Qinling Mountain Region, Shanxi Province, China. Saarbrucken: VDM Verlag Dr. Muller. 